\title{
Artificial Neural Network Model for FRP Shear Contribution of RC Beams Strengthened with Externally Bonded FRP Composites
}

\author{
Weiwen $\mathrm{LI}^{1}$, Xiaoli REN ${ }^{2}$, Chengyue HU* \\ School of Civil Engineering \\ Guangdong Province Key Laboratory of Durability for Marine Civil Engineering, Shenzhen University \\ Shenzhen, China \\ e-mail: liweiwen@szu.edu.cn, renli727345099@163.com, " huchengyue1028@163.com
}

\begin{abstract}
Fiber reinforced polymers (FRP) have been widely used in retrofitting or strengthening concrete structures in recent years. This is due to the various advantages of FRP composites, including high strength-weight ratio, high tensile modulus, superior corrosion resistance and ease of applying in strengthening applications. One of the most important applications of FRP is shear strengthening for reinforced concrete (RC) beams. In this paper, two different artificial neural network (ANN) models are proposed for predicting the FRP shear contribution of $\mathrm{RC}$ beams strengthened in shear with U-wrapping FRP sheets with/without additional anchorage system, respectively. To verify the accuracy of the ANN models, the predictions from five existing design guidelines are applied to comparison. It is found that the proposed ANN models can improve the accuracy of predicting the shear contribution for U-wrapping FRP configuration whether with anchorage or without one.
\end{abstract}

Keywords-artificial neural network; fiber reinforced polymer $(\mathrm{FRP})$; reinforced concrete $(\mathrm{RC})$ beam; shear-strengthening

\section{INTRODUCTION}

Fiber reinforced polymers (FRP) have been widely used in retrofitting or strengthening reinforced concrete (RC) structures in recent two decades. This is due to the various advantages of FRP composites, including high strengthweight ratio, high tensile modulus, superior corrosion resistance and ease of applying in strengthening applications. One of the most important applications of FRP is shear strengthening for reinforced concrete (RC) beams. The shear behavior of RC beams shear-strengthened with externally bonding (EB-) FRP composites have been widely studied by researchers all over the world,and many experiments[1-3] have been conducted in the last 30 years. With more and more practical applications of FRP composites in civil engineering, various design guidelines for strengthening concrete structures with EB-FRP composites have been released since the 2000s, such as GB 50608[4], ACI 440.2R[5], fib-TG 9.3[6], JSCE[7] and CIDAR[8]. However, these design guidelines are usually developed from a limited and somewhat arbitrary subset of these test results, and they did not consider the influence of some important factors to the performance of the FRP shear-strengthening RC beams, such as the effect of shear span-to-effective depth ratio. By recent years, a new method is developed. It is to collect the experimental data of the existing tests and analysis the comprehensive performance of them. By this way, the authors can comprehensively understand the recent research status and it can help the authors to determine the meaningful research direction. It is also convenient to validate and evaluate of the existing design guidelines. A database was collected in this article. 163 experimental data of strengthened RC beams with U-wrapping FRP strips were collected from literature. The U-wrapping configuration in the database was divided into two small databases according to with/without anchorage.

In recent decades, Artificial Neural Networks (ANN) theory have been used to predict concrete properties. ANN is a powerful tool for system modeling in a wide range of applications. Therefore, the advanced ANN models are proposed in this study, which were intended for predicting the contribution of FRP reinforcements. To verify the accuracy of the ANN models, the predictions from existing design guidelines are applied to compare with that of the ANN models.

\section{ARTIFICIAL NEURAL NETWORKS (ANNS)}

\section{A. Database}

163 experimental results of RC beams strengthened with U-wrapping FRP reinforcements were collected from the literature[3,9-11]. The U-wrapping configuration in the database was divided into two small databases according to the with/without the anchorage. For the U-wrapping configuration without anchorage, the experimental data are 94, as well as 69 for the U-wrapping configuration with anchorage.

\section{B. Neural Network Models of FRP Strengthened Beams without Anchorage}

For predicting the FRP shear contribution, the neural network toolbox of MATLAB is used as the ANN analysis. There are 94 experimental data were collected from the literature [3, 9-11]. The selected experimental results were randomly divided into three parts: $70 \%$ of data used to train the ANN model, $15 \%$ of data used to verify the model, and the other $15 \%$ used to test it.

For the beam without anchorage, 10 important parameters are selected as input parameters for the prediction of the shear strength of RC beams including: concrete compressive strength (fc), shear span-to-depth ratio $(\lambda)$, the stirrup ratio ( $\rho s v)$, effective depth of the beam (d) and beam width (bw), the thickness of the FRP ( $n * t f)$, ultimate strain of FRP( $\varepsilon f u$ ), the width of the FRP (wf), the spacing of the FRP (sf), the elasticity modulus of the FRP (Ef). 
TABLE I. COMPARISON RESULTS OBTAIN USING ANN MODEL (WITHOUT ANCHORAGE) AND DIFFERENT GUIDELINES

\begin{tabular}{|c|c|c|c|c|c|}
\hline Strengthening Model & \multicolumn{5}{|c|}{ Important Statistical Parameters } \\
\hline fib-TG 9.3[6] & 0.87 & 0.55 & 0.64 & 0.41 & $42.85 \%$ \\
\hline ACI $440.2 \mathrm{R}[5]$ & 0.67 & 0.45 & 0.68 & 0.34 & $49.35 \%$ \\
\hline CIDAR[8] & 0.75 & 0.41 & 0.55 & 0.46 & $43.99 \%$ \\
\hline GB 50608[4] & 1.73 & 0.98 & 0.56 & 0.49 & $57.01 \%$ \\
\hline
\end{tabular}

TABLE II. COMPARISON RESULTS OBTAIN USING ANN MODEL (WITH ANCHORAGE) AND DIFFERENT GUIDELINES

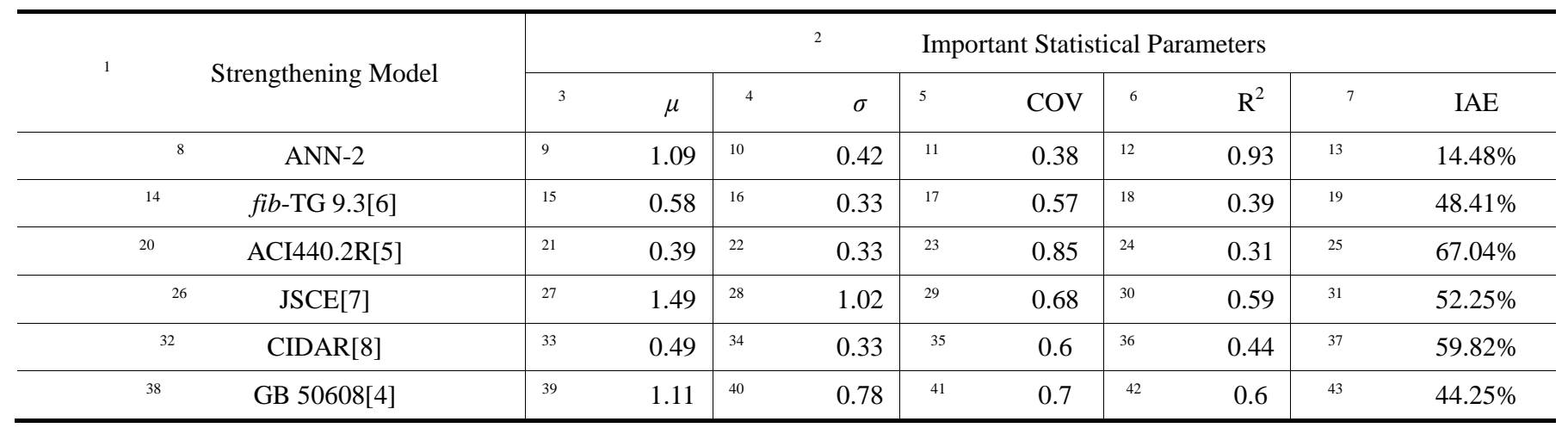

The type of neural network is the BP neural network. The model has one hidden layer with 12 nodes, one input layer with 10 nodes and output layer with one node giving contribution of FRP reinforcements. the algorithm of BP is LM algorithm, the training function is named as Trainlm, the learning algorithm of weights and thresholds is Learndm, the propagation function of the hidden layer is Tansig, the propagation function of the output layer is purelin, and the performance function of the neural network is MSE. the time of training is 1000, the network performance objectives is $1 \mathrm{e}-5$, the largest number of failed verification is 10 , the learning rate is 0.01 .

\section{Neural Network Models of FRP Strengthened Beams with Anchorage}

There are 69 experimental data in this analysis. 10 important parameters are selected as input parameters as same as the beam without anchorage. The type of neural network is the BP neural network. The model has one hidden layer with 8 nodes, one input layer with 10 nodes and output layer with one node giving contribution of FRP reinforcements. the algorithm, training function, the learning algorithm of weights and thresholds, the propagation function and the rest of the parameters are as same as the analysis for U-wrapping FRP configuration without anchorage.

\section{Predicted Results using ANN and Design Proposals}

Figure 1 and Figure 2 shows the comparison between observed and predicted values of the ANN model and five existing design guidelines. As can be seen from this figure, ANN has performed well in predicting the shear contribution of the FRP. Table1 shows the summary of the predicted results and the ratio of predictions of ANN and FRP guidelines which the beam has no anchorage. This study measures the accuracy of the predicted results by using three important statistical parameters: Correlation Coefficient R2, Integral Absolute Error (IAE) and Coefficient of Variation (CV). R2 value can demonstrate the statistical relationship of correlation, while $\mathrm{CV}$ value can provide a standardized measure of dispersion of a probability distribution for the Vf,pre /Vf,exp (Prediction/Experiment) ratios. The definition of IAE is as follows:

$$
I A E=\sum \frac{\sqrt{(\text { Expe. }-\mathrm{Pr} e d .)^{2}}}{\sum \mid \text { Expe. } \mid}
$$




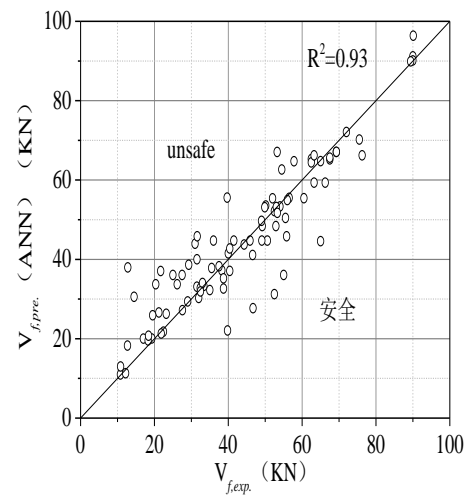

(a) ANN-1

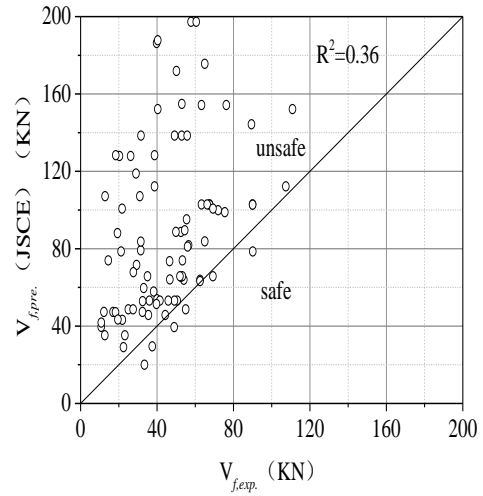

(d) JSC

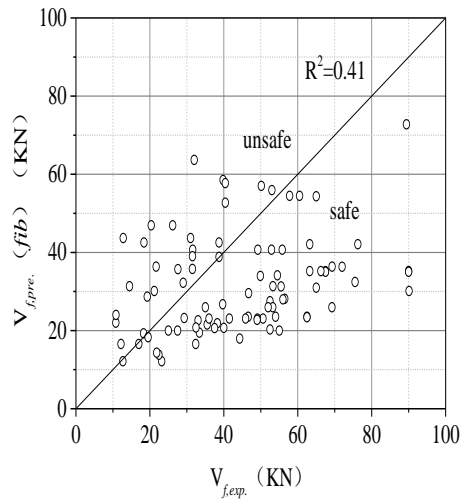

(b) fib-TG 9.3

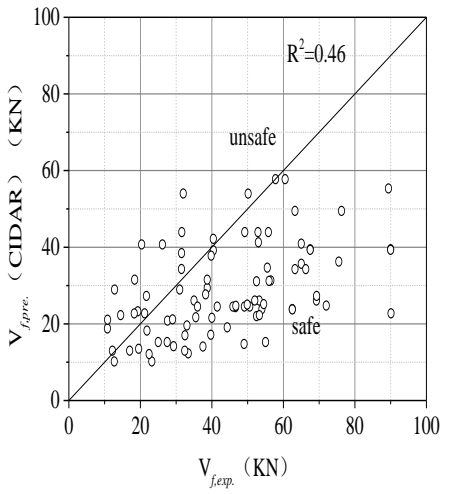

(e) CIDAR

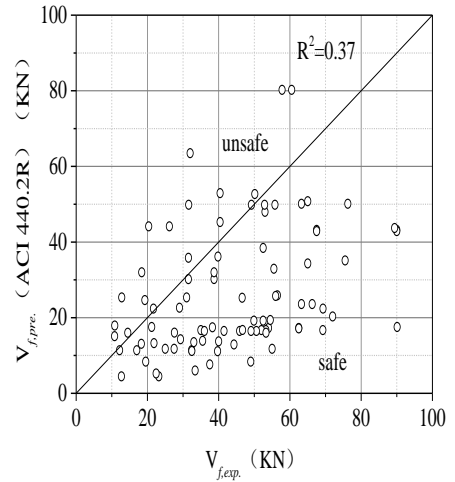

(c) $\mathrm{ACI} 440.2 \mathrm{R}$

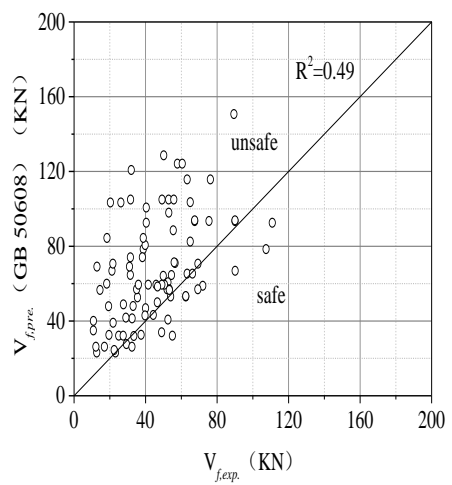

(f) GB 50608

Figure 1. Observed and predicted FRP shear contribution from ANN model and various design guidelines (Without anchorage).

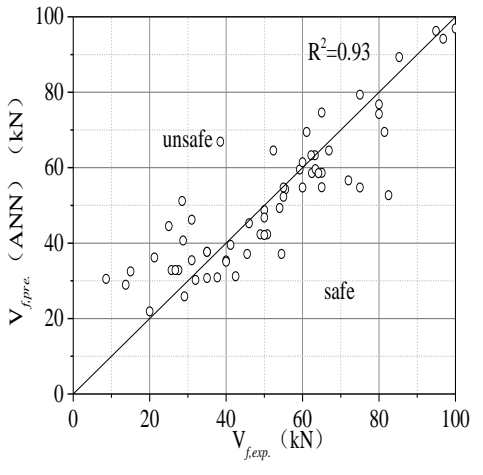

(a) ANN-1

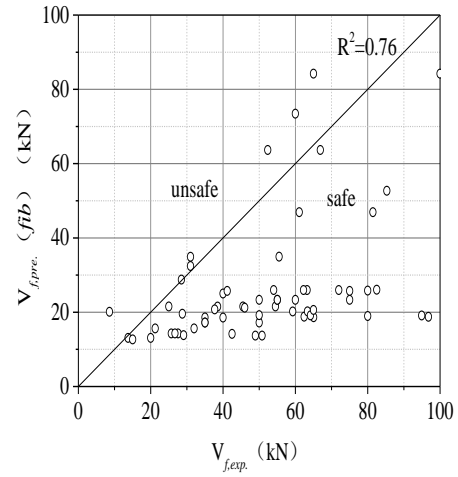

(b) fib-TG 9.3

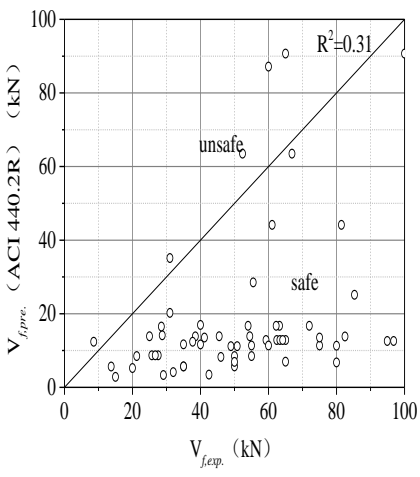

(c) $\mathrm{ACI} 440.2 \mathrm{R}$ 


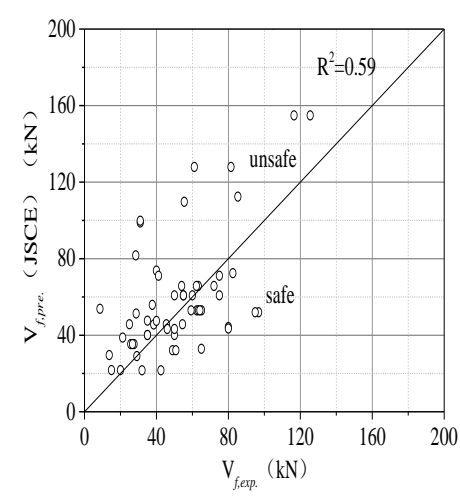

(d) JSCE

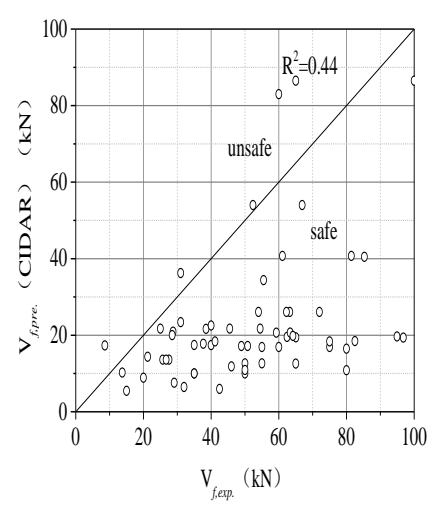

(e) CIDAR

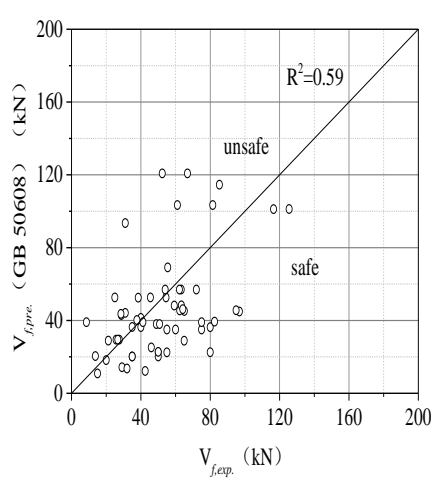

(f) GB 50608

Figure 2. Observed and predicted FRP shear contribution from ANN model and various design guidelines (With anchorage).

From table 1 and table 2 shows that the ratio of predictions of the neural network model, the average is the nearest to 1.0, R2 is the largest, IAE and $\mathrm{CV}$ are minimum. According to the results, the neural network model predicted better than those obtained from the equations of five existing design guidelines.

\section{CONCLUSIONS}

In this paper, an artificial neural network model is proposed to predict the FRP shear contribution for RC beams strengthened with U-wrapping FRP sheets with/without anchorage system. Although the shear span-to-depth ratio is one of the most efficient parameter that directly affects the ultimate shear behavior, various existing design equations do not consider this important factor. However, the ANN models take into account the effect of shear span-to-depth ratio. The proposed ANN model is evaluated based on the comparison with five existing design guidelines. The results show that the ANN models are more accurate than these existing design guidelines. Besides, the number of the data in the database is limited, the ANN model can be improved by adding new experimental data to the model.

\section{ACKNOWLEDGMENT}

The financial support of this study by the National Natural Science Foundation of China (Grant No. 51678365) are gratefully acknowledged.

\section{REFERENCES}

[1] Sato $\mathrm{Y}$, Ueda $\mathrm{T}$, Kakuta $\mathrm{Y}$, et al. Ultimate shear capacity of reinforced concrete beams with carbon fiber sheets. [C]. 1997.: 499506.

[2] Khalifa A. Shear Performance of Reinforced concrete beams strengthened with advanced composites[D]. PhD thesis, Department of Structural Engineering, University of Alexandria, Egypt, 1999.

[3] Belarbi A, Bae S, Brancaccio A. Behavior of full-scale RC T-beams strengthened in she

[4] ar with externally bonded FRP sheets[J]. Construction and Building Materials, 2012, 32: 27-40.

[5] China engineering construction standardization association. Technical specification for concrete structures of carbon fiber sheet reinforcement CECS146:2003(2007)[S]. Beijing, 2007.

[6] ACI-440.2R. Guide for the design and construction of externally bonded FRP systems for strengthening concrete structures [S]. American Concrete Institute, Farmington Hills, Michigan, USA, 2008.

[7] fib. Externally bonded FRP reinforcement for RC structures [S]. TG 9.3, Int. Federation for structural Concrete, Lausanne, Switzerland, 2001.

[8] JSCE. Recommendations for upgrading of concrete structures with use of continuous fiber sheets[S]. Japan Society of Civil Engineers, 2001.CIDAR. Design guideline for RC structures retrofitted with FRP and metal plates: Beams and slabs[S]. Australia: The Univ. of Adelaide, 2006.

[9] Sas G. FRP Shear Strengthening of Reinforced Concrete Beams[D]. Sweden, 2011.

[10] Mofidi A. Shear strengthening of reinforced-concrete beams using advanced composite materials[D]. École de technologie supérieure, 2012.

[11] Koutas L, Triantafillou T C. Use of anchors in shear strengthening of reinforced concrete T-beams with FRP[J]. Journal of Composites for Construction, 2012, 17(1): 101-107 